EGU21-250

https://doi.org/10.5194/egusphere-egu21-250

EGU General Assembly 2021

(c) Author(s) 2021. This work is distributed under

the Creative Commons Attribution 4.0 License.

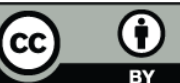

\title{
Identification and interpretation of seismic short-duration events inside the Kolumbo submarine volcano in the Southern Aegean
}

\author{
Florian Schmid ${ }^{1}$, Jens Karstens ${ }^{1}$, and Paraskevi Nomikou ${ }^{2}$ \\ ${ }^{1}$ GEOMAR - Helmholtz Zentrum für Ozeanforschung, Marine Geophysics, Kiel, Germany (fschmid@geomar.de) \\ ${ }^{2}$ National and Kapodistrian University of Athens, Greece
}

Kolumbo represents one of the most hazardous, currently active, volcanoes in the eastern Mediterranean. Its last eruption in 1650 AD was associated with a vast explosion, causing a tsunami of regionally devastating impact. The eruption was also associated with the voluminous and rapid release of toxic gases asphyxiating humans and animals on the nearby Islands. Earthquake records from the recent decades document on-going unrest beneath the volcano. Remotely operated vehicle dives revealed several hydrothermal vent sites and bacterial mats at the crater floor, which are concentrated near the northern crater wall. The vents emit mainly $\mathrm{CO}_{2}$, leading to the accumulation of acidic waters in the crater. Accordingly, one of the main volcanic hazards associated with Kolumbo is that rapid overturning of water in the crater may release harmful amounts of toxic gases. Monitoring the hydrothermal processes inside the Kolumbo crater will provide an important contribution to the understanding and evaluation of this and other volcanic hazards.

In October 2019, we deployed an ocean bottom seismometer and hydrophone (OBS/H) inside the Kolumbo crater. During the four days of passive recording we identified about 100 so-called short duration seismic events, which were only present on the seismometer channels, while generally being absent on the hydrophone channels. The events have durations of less than one second with dominant frequencies between 5 to $30 \mathrm{~Hz}$. Most of the events represent well-polarized seismic phases, which enables us to determine their azimuth angle (with a 180-degree bias) and angle of incidence at the $\mathrm{OBS} / \mathrm{H}$. We cross-correlated all polarized seismic waveforms and subsequently used the cross-correlation coefficients for a hierarchical cluster analysis to elaborate whether the events have a random origin or originated from a common origin. Our analysis revealed that the majority of events is associated with two clusters. The azimuth angles of all events in the largest cluster coincide with the azimuth angle between station and the field of hydrothermal vents and bacterial mats inside the crater. This coincidence suggests that the origin of the short duration events is associated with the sub-seafloor migration of fluids or the fluid discharge process at the crater floor. In fact, short-duration events of similar characteristics, recorded by $\mathrm{OBS} / \mathrm{H}$, were previously attributed to sub-seafloor fluid migration and the discharge of fluids at the seafloor. Our analyses indicate that seismic monitoring of submarine volcanoes should include the detection and analysis of short duration events, which may act as a novel tool in the characterization of volcanic unrests and volcanogenic geohazard monitoring in general. 
